\title{
Soft tissue augmentation with volume stable collagen matrix: Two cases report
}

\author{
Do-Hyung Kim ${ }^{1,2}$, Seong-Nyum Jeong ${ }^{1,2}$, Jae-Hong Lee ${ }^{1,2 \star}$ \\ ${ }^{1}$ Department of Periodontology, Wonkwang University Daejeon Dental Hospital, Wonkwang University College of Dentistry, Daejeon, Korea \\ ${ }^{2}$ Institute of Wonkwang Dental Research, Wonkwang University College of Dentistry, Iksan, Korea
}

Soft and hard tissue volume around natural teeth and dental implants, is crucial for esthetics and long-term maintenance. Studies have described guided bone regeneration (GBR), as a predictable method to maintain or augment hard tissue volume, around teeth and dental implants. For soft tissue volume, collagen matrix showed reliable results, and less post-operative pain in many studies. The purpose of this case report, is to assess the outcome of GBR with volume stable collagen matrix (VSCM), around natural teeth and dental implants. In two cases, GBR with VSCM was performed, to augment soft and hard tissue volume around natural teeth and dental implants, respectively. Both cases showed clinically acceptable esthetics and periodontal parameters, up to 6 and 12 months per respective follow up. As our results show, GBR using VSCM can achieve successful outcomes.

Key Words: Bone regeneration, Dental implants, Guided tissue regeneration, Membranes

(c) This is an open-access article distributed under the terms of the Creative Commons Attribution Non-Commercial License (http://creativecommons.org/licenses/by-nc/4.0) which permits unrestricted noncommercial use, distribution, and reproduction in any medium, provided the original work is properly cited.

\section{INTRODUCTION}

Maintaining hard and soft tissue volume around teeth or dental implant is crucial for esthetics and maintenance of teeth and dental implants. Relationship between soft tissue and marginal bone level around dental implants already had been well documented [1,2]. Thin buccal mucosa and alveolar bone cause gingival recession and bone resorption around dental implants which result in aesthetic and cleansing problem [3]. In addition, according to recent studies about hard tissue around dental implants, showing that implant placement or loading cannot prevent the loss of buccal bone width, maintaining buccal bone thickness of the dental implants may affect the long-term success and esthetics of the implant [4].

Guided bone regeneration (GBR) is common procedure for augmentation of hard tissue volume around teeth or dental implants. For GBR, bone substitutes such as autogenous bone, allografts, xenografts, alloplasts, and membranes such as non-resorbable or resorbable membrane are used. Bone substitutes used in GBR have ability of osteogenesis, osteoinduction, and osteoconduction depending on the type of bone material and barrier membranes have ability to maintain the shape of bone material and to exclude epithelial cells [5]. Conventionally, non-resorbable expanded-polytetrafluoroethylene (e-PTFE) membrane was mainly used, but due to the frequent exposure of membrane and additional need of surgery to remove mem-

Received April 9, 2019; Revised May 9, 2019; Accepted May 20, 2019

Corresponding author: Jae-Hong Lee, Department of Periodontology, Wonkwang University Daejeon Dental Hospital, Wonkwang University College of Dentistry, 77 Dunsan-ro, Seo-gu, Daejeon 35233, Korea.

Tel: +82-42-366-1114, Fax: +82-42-366-1115, E-mail: ljaehong@gmail.com

Copyright $\odot$ 2019, Oral Biology Research Institute 
brane, collagen based resorbable membrane is successfully used recently [5].

Subepithelial connective tissue graft (sCTG) is considered as a gold standard for soft tissue augmentation but SCTG has problem of post-operative discomfort, variation in quality and quantity of graft and increased operation time [6]. Due to these disadvantages of sCTG, several alternatives have been studied, and the use of collagen matrix has successfully resulted in soft tissue thickness augmentation around natural teeth and dental implants $[7,8]$. Froum et al. [8] reported statistically significant difference in mucosal thickness after 3 months of surgery between untreated group and collagen matrix group. They also found that there was no significant difference in pain and discomfort between untreated group and collagen matrix group.

The purpose of this case report is to describe the effects of simultaneous GBR and soft tissue augmentation around periodontally compromised teeth and dental implant, where the volume of soft and hard tissue deficiency is predicted after open flap debridement and implant surgery using volume stable collagen matrix (VSCM).

\section{CASE}

\section{Case 1: Simultaneous GBR with VSCM during implant placement}

Forty-six years old female patient was refered to Periodontal Department from Prosthodontic Department. Her chief complaint was to restore upper right incisor (\#11) with implant supported fixed crown. \#11 was extracted due to trauma about 5 months ago and healing of extraction socket was fine (Fig. 1). Patient had a hyperlipidemia but no other general health problems which can compromise implant installation. Patient were administered antibiotic (netilmicin $50 \mathrm{mg} / \mathrm{mL}$ ) and analgesics (dicolfenac 90 $\mathrm{mg} / 2 \mathrm{~mL}$ ) injection 30 minutes before implant surgery, and provided with the following post-operative medication and mouthwash to be used after implant surgery: antibiotics (amoxicillin $500 \mathrm{mg}$ three times daily [tid] for 5 days), analgesics (ibuprofen $200 \mathrm{mg}$ tid for 5 days), anti-inflammatory drug (prednisolone $10 \mathrm{mg}$ tid for 3 days), and antimicrobial rinse (GUM Activital; Sunstar, Osaka, Japan). The local anesthetics (2\% lidocaine HCL with 1:100,000 epinephrine; Yuhan, Seoul, Korea) were injected at surgical site. Intrasulcular incision on \#13,12, 21 and crestal incision on \#11 were done with \#12,15, 15c blade and an Orban knife (Hu-Friedy, Chicago, IL, USA). After incision and flap elevation, mesial side of implant install site shows labio-palatal direction ridge atrophy. Implant with $3.5 \mathrm{~mm}$ width and 10 mm length (TSIII; Osstem Implant Co, Seoul, Korea) was installed (Fig. 2). After implant installation, GBR with releasing incision was done with deproteinized bovine bone material-collagen ([DBBM-C], 250 mg, Geistlich Bio-Oss Collagen; Geistlich Pharma AG, Wolhusen, Switzerland), native bilayer collagen membrane $(13 \times 25 \mathrm{~mm}$, Bio-Gide; Geistlich Pharma AG), and VSCM $(15 \times 25 \mathrm{~mm}$, Ossix Volumax; Datum Dental, Telrad, Israel) with $1 \mathrm{~mm}$ thickness on atrophic ridge. VSCM was added on labial side of alveolar ridge to augment soft tissue volume. Surgical site was sutured with 4-0 e-PTFE (Biotex; Purgo Biologics, Seongnam, Korea) and 5-0 nylon (Monosof; Covidien, Dublin, Ireland)
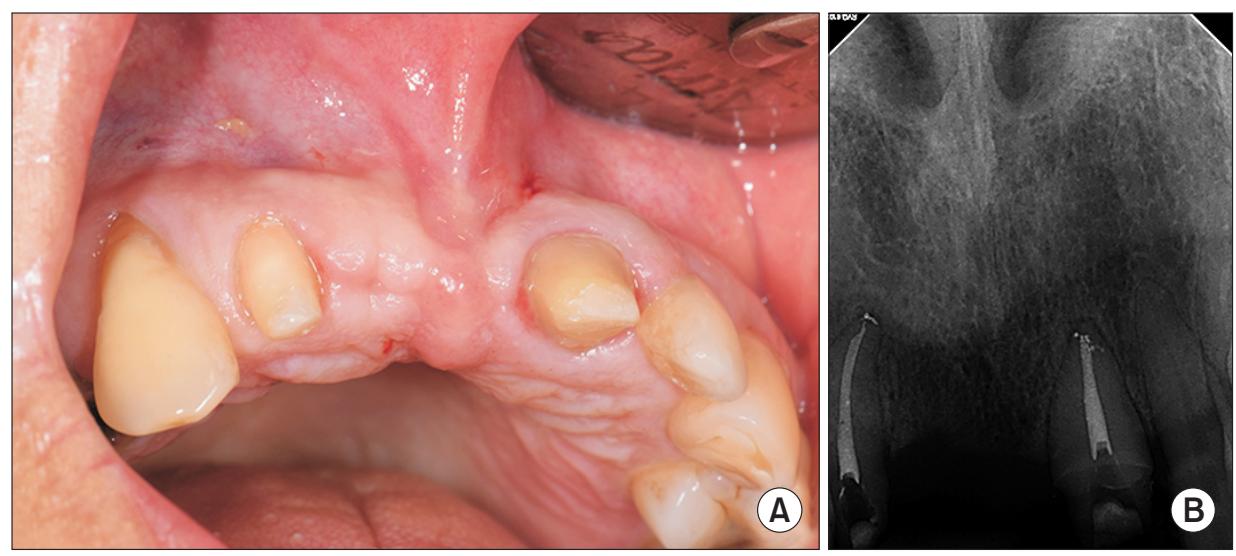

Fig. 1. Initial intraoral photograph and radiograph of Case 1 patient. (A) Good healing with labial slight labiopalatal ridge atrophy was found at first visit. (B) Completely healed socket is shown on the radiograph. 

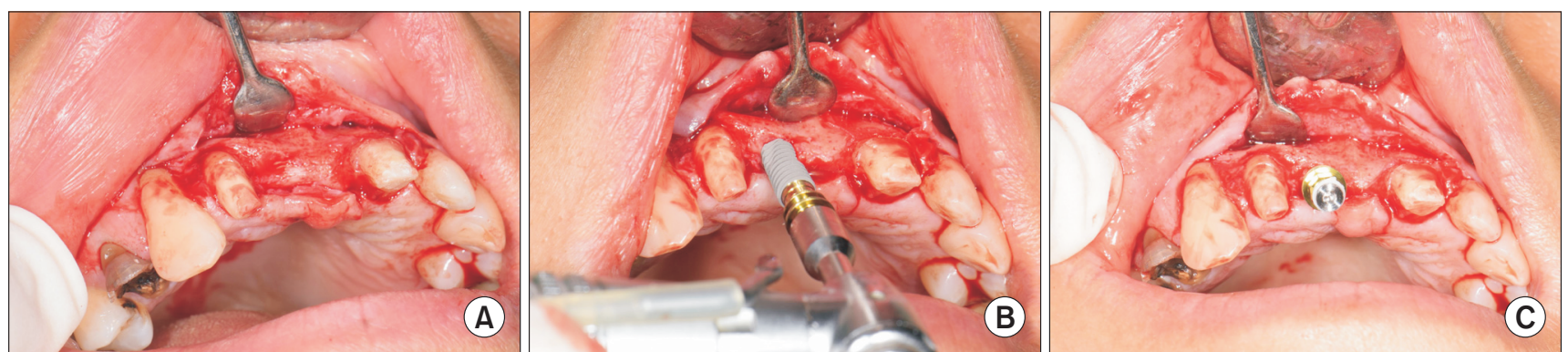

Fig. 2. Implant installation of Case 1 patient. (A) Flap elevation. (B) Labio-palatal direction ridge atrophy was detected before implant installation. (C) After implant installation.
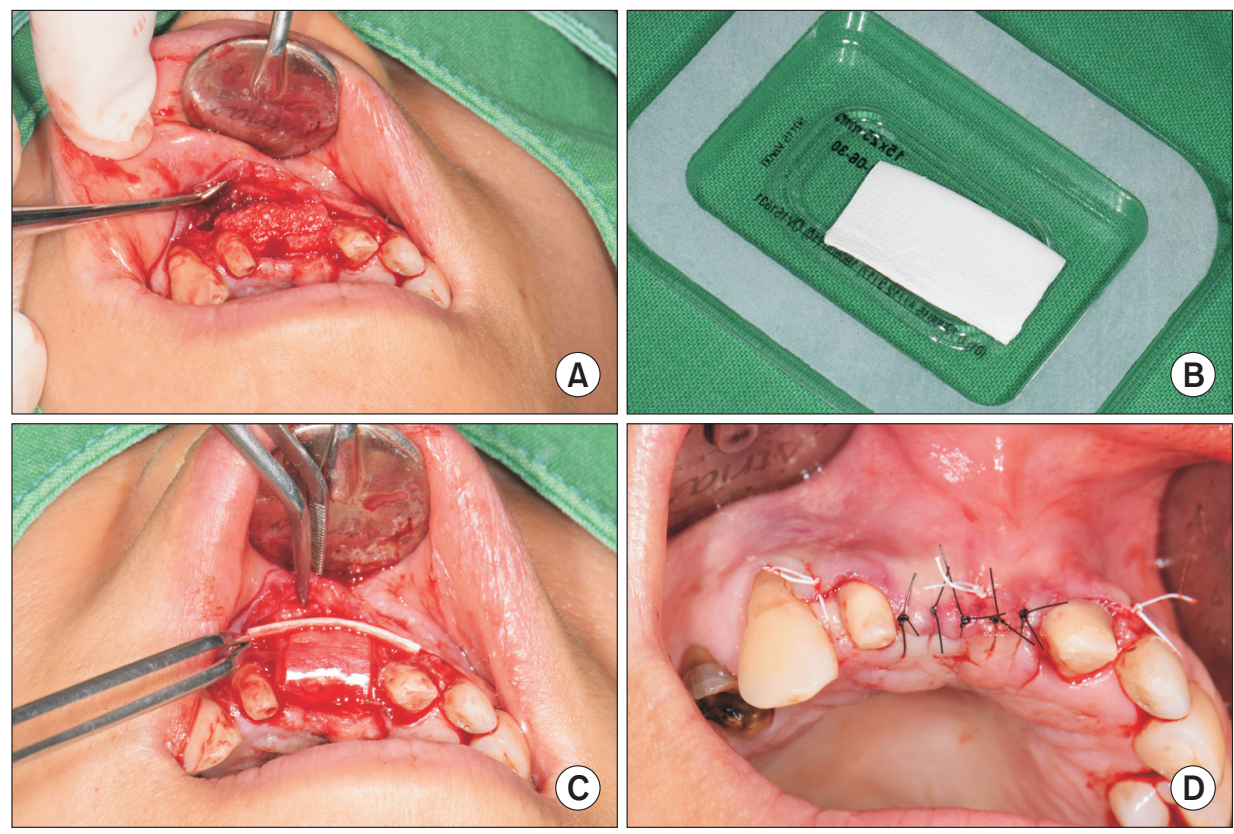

Fig. 3. Guided bone regeneration with deproteinized bovine bone materialcollagen (DBBM-C), native bilayer collagen membrane, and volume stable collagen matrix (VSCM). (A) DBBM$\mathrm{C}$ was applied at labial side of implant. (B) VSCM before use. (C) VSCM was applied on labial side of DBBM-C. (D) Sutured with expanded-polytetrafluoroethylene and nylon.
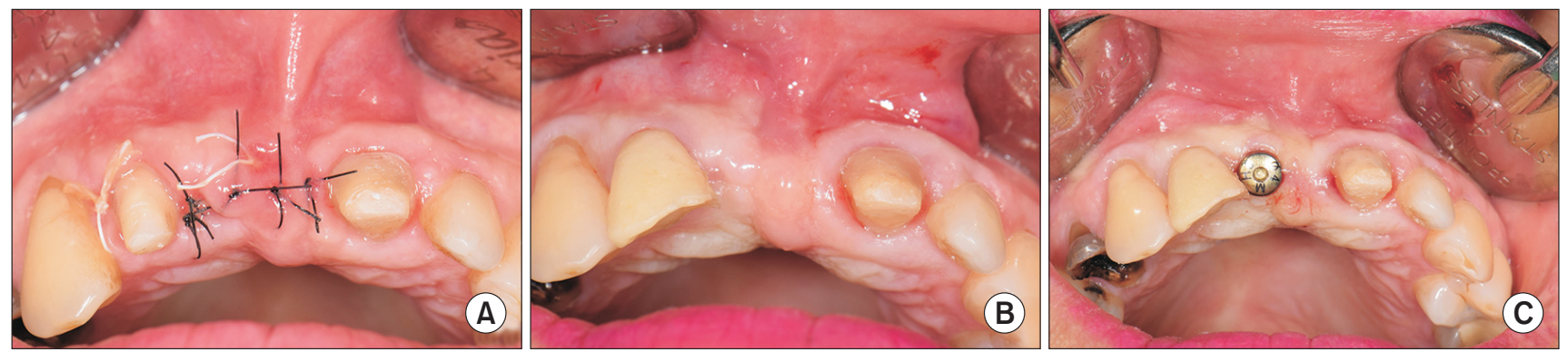

Fig. 4. Surgical site after 2 weeks and 5 months. (A) Healed uneventfully after 2 weeks. (B) Before the implant second surgery. (C) After healing abutment placement.

using modified horizontal mattress and interrupted suture method (Fig. 3). Two week after surgery, stitch out was done. Augmented soft tissue and hard tissue compared with initial visit were observed. Augmented tissue was well maintained until 2nd surgery (Fig. 4). At one year follow up and final prosthesis delivery, augmented tissue was well maintained clinically and radiographically showing periodontal pocket depth (PPD) within $3 \mathrm{~mm}$ and $2 \mathrm{~mm}$ of 
stable buccal volume, which was changed about 30\% after surgery, no bleeding on probin (BOP). And patient was satisfied with esthetics (Fig. 5).

\section{Case 2 : Simultaneous GBR with VSCM during open flap debridement}

Forty years old female patient visited our Periodontal Department to get overall periodontal treatment. Patient had generalized alveolar bone loss in panoramic radiograph, especially on mesial side of upper left caine (\#23) with 8 mm of buccal, mesial PPD (Fig. 6). Patient showed moder- ate oral hygiene. Scaling and root planing of upper, lower anterior region and open flap debridement of upper, lower posterior region was planned. At the open flap debridement of \#23, the local anesthetics were injected at surgical site. After anesthesia, modified flap including mesial side of \#22 to distal side of \#27 was elevated. After flap elevation, sub-gingival calculus was detected on the buccal side of \#23. Large bone defect was observed within surgical site and gingival recession after surgery was expected. To maintain soft and hard tissue volume after surgery, GBR with soft tissue augmentation using xenegrafts (The graft; Purgo Biologics) and VSCM was planned. Thorough de-
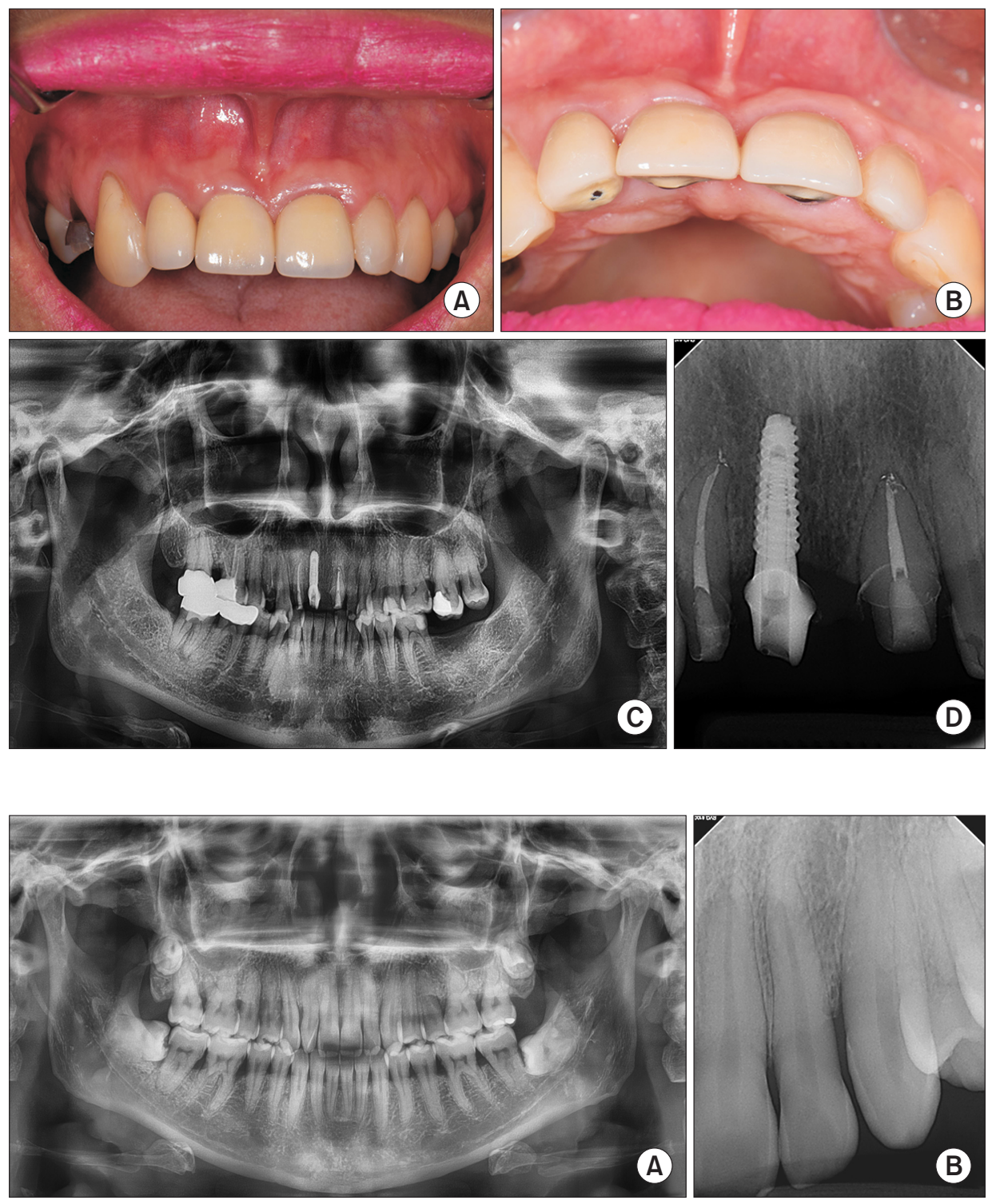

Fig. 6. Panorama and intra-oral radiograph of Case 2 patient. (A) Generalized bone loss was found at first visit. (B) Severe bone loss at mesial side of maxillary left canine was found. 
bridement of calculus and granulation tissue using ultrasonic scaler (KaVo, Biberach, Germany) and gracey curette (Hu-Friedy) followed by root conditioning with tetracycline (Chong-Kun-Dang, Seoul, Korea) cotton was done. After these procedure, GBR with xenograft particle and VSCM was done. Surgical site was sutured with modifed Gottlow suture method using 4-0 e-PTFE (Fig. 7). At 2 week check period, total tissue volume seemed to be well maintained. After 6 months of surgery, $0.5 \mathrm{~mm}$ of recession on \#22 disto-buccal side, $1 \mathrm{~mm}$ of recession on \#23 were occurred but this recession was due to the bone loss of surgical site and clinically acceptable. Other clinical parameters like BOP and PPD were within in normal limit and patient were satisfied with esthetics of surgical site (Fig. 8).

\section{DISCUSSION}

In this case report, we introduced the cases which needed soft and hard tissue augmentation around natural teeth and dental implants. In Case 1, simultaneous hard tissue and soft tissue augmentation using collagen matrix with DBBM-C was performed during implant installation. In Case 2, hard and soft tissue augmentation was performed in upper anterior region, using collagen matrix and xenografts, due to extensive buccal bone resorption which expected to cause poor esthetics and gingival recession. In both cases, simultaneous GBR and soft tissue augmentation were done because of the surgical site. Since anterior region is aesthetically critical, staged soft tissue augmentation would lower the patient's satisfaction. Lin et al. [9] reported that staged and simultaneous soft tissue augmentation around implant showed no statistical difference in terms of
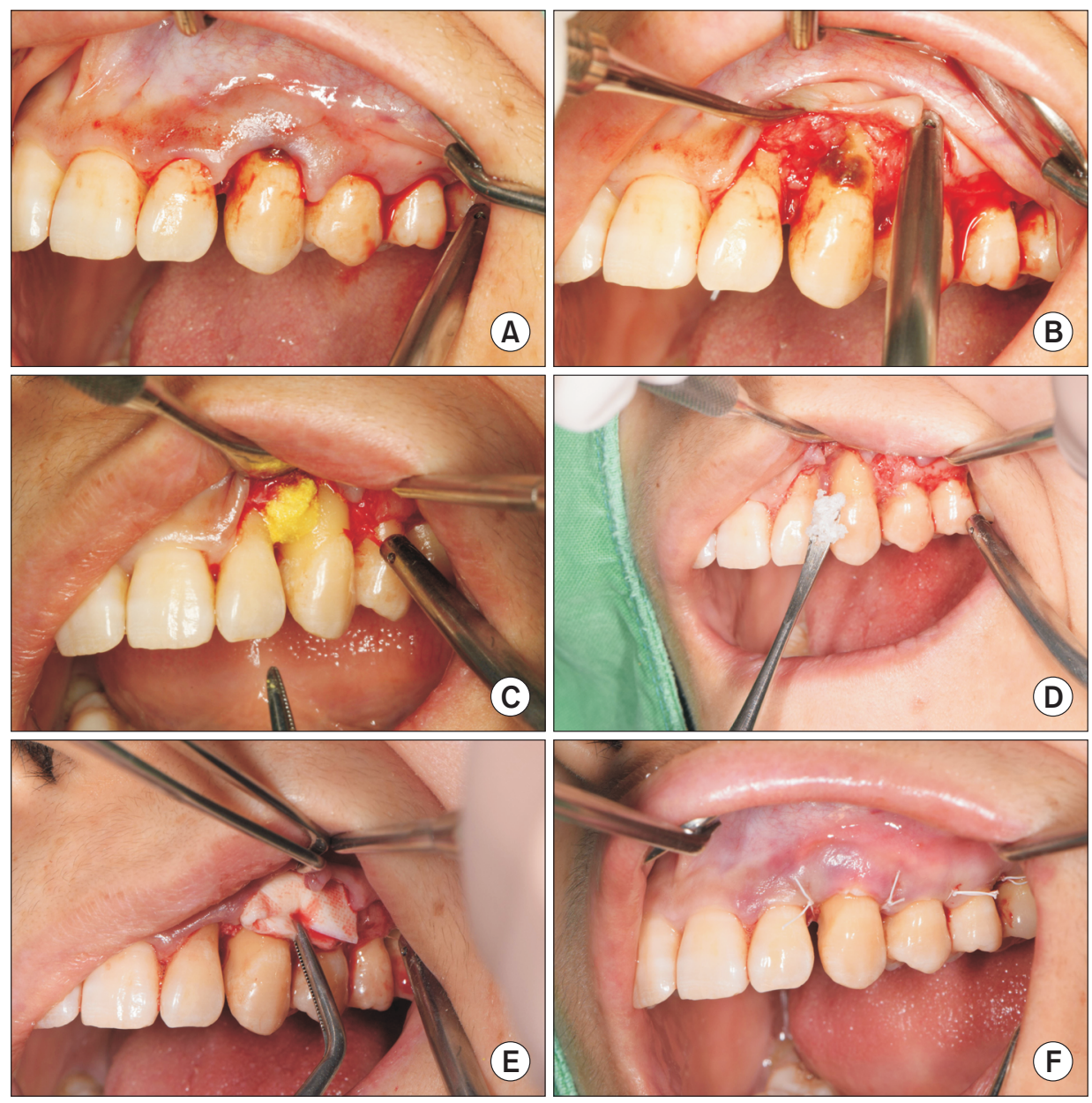

Fig. 7. Surgical procedure of Case 2 patient. (A) Immediately after the intra-sulcular incision was done. (B) Sub-gingival calculus was found after flap elevation. (C) Root surface conditioning with tetracycline cotton. (D) Xenografts were applied at the mesial side of upper left canine. (E) Volume stable collagen matrix was applied at the labial side of upper left canine. (F) Suture with expanded-polytetrafluoroethylene. 

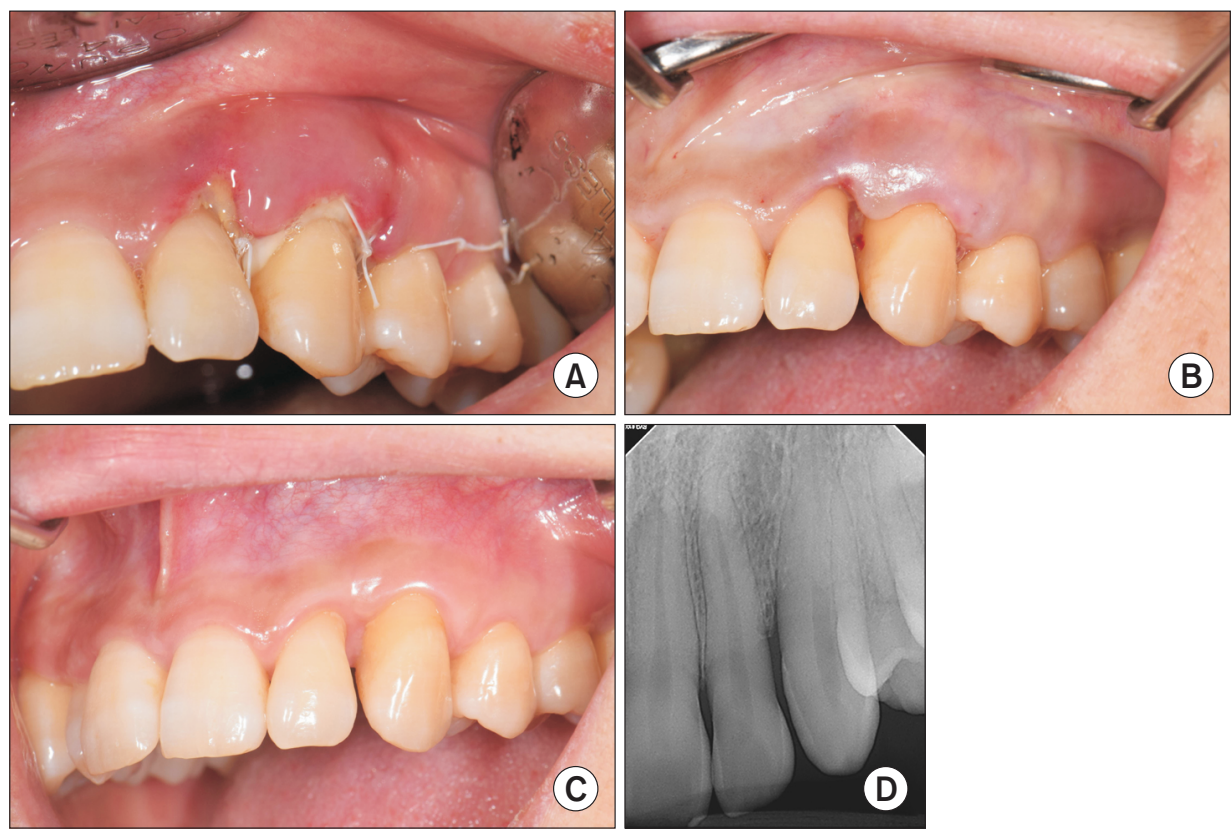

Fig. 8. Surgical site after 1-, 2-weeks, and 6 months. (A) Labial volume seemed to be maintained after 1 week stitch out. (B) Surgical site healed uneventfully at 2 weeks after surgery. (C) Surgical site after 6 months. (D) Intraoral radiograph after 6 months.

keratinized tissue width and soft tissue thickness.

In cases 1 and 2 with respective follow up period of 6 and 12 months, soft tissue as well as hard tissue volume were properly maintained. Dental implant and teeth were also maintained uneventfully with good clinical parameters. Thoma et al. [6] reported similar results (soft tissue thickness at the most coronal level at 1 month using collagen matrix: $2.1 \pm 1.6 \mathrm{~mm}$; using sCTG: $2.5 \pm 1.7 \mathrm{~mm}$ ) and statistically insignificant difference between SCTG and collagen matrix at 1 and 6 months period in the canine model. $\mathrm{Hu}-$ ber et al. [10] also reported successful result at 1 year follow up of soft tissue augmentation around dental implants with sCTG and collagen matrix. In this case report, soft tissue volume shrinkage, measured by periodontal probe, is about $30 \%$ in Case 2 and $0.5 \mathrm{~mm}$ gingival recession was occurred clinically in Case 1 which is similar to previous studies $[6,10]$.

Patients in all cases showed mild pain during or after surgery, and healed without complication such as pus discharge or inflammation. Since there were no connective tissue harvesting procedure, reduced surgical time and no discomfort of harvested site were shown which are similar to previous studies. Tonetti et al. [7] reported 15 minutes and 11.9 point of statistically significant reduction in surgical time and visual analogue scale reduction respectively.
In this case report, use of VSCM reduced surgical time compared to $\mathrm{SCTG}$ and this reduction is expected to reduce postoperative discomfort and promote wound healing.

Several type of collagen matrices are commercialized in the market. Among them, collagen matrix consists of type 1,3 derived from porcine tendon shows physiologic reaction caused by monocyte when applied to human body [11]. But non-cross-linked collagen membranes often lose its property too early and decompose inside human body. Tal et al. [12] reported that non-cross-linked collagen membranes were not observed in the biopsy specimen obtained at 6 months post-operation re-entry surgery.

To complement fast absorption, several chemical and physical cross linking methods were developed in past but cytotoxicity and side-effects occurred [13]. But recent advancement and development of cross-linking methods make cross-linked collagen membrane possible to show similar biocompatibility and results compared to non-cross linked collagen membrane [14]. VSCM, used in this case report, has outer layers which made from refined porcine derived collagen, glycated by ribose, and inner porous layer. This structure makes collagen matrix possible to maintain soft tissue volume effectively. In in-vivo study, above mentioned collagen matrix maintains its occlusive property to human and murine cell infiltration 30 days and shows abil- 
ity to use it as a barrier membrane in GBR procedure [15].

This product showed biocompatibility and is considered to have ability to replace sCTG in soft tissue augmentation or volume maintenance. And simultaneous GBR and soft tissue augmentation using VSCM in above 2 cases was successful throughout follow up period. Further randomized controlled trial or histological study to evaluate clinical, histological effectiveness is needed.

\section{ACKNOWLEDGEMENTS}

This research was supported by Wonkwang University in 2019.

\section{CONFLICTS OF INTEREST}

The authors declare that they have no competing interests.

\section{ORCID}

\author{
Do-Hyung Kim \\ https://orcid.org/0000-0001-7846-6175 \\ Seong-Nyum Jeong \\ https://orcid.org/0000-0003-4890-989X \\ Jae-Hong Lee \\ https://orcid.org/0000-0002-2375-0141
}

\section{REFERENCES}

1. Hutton CG, Johnson GK, Barwacz CA, Allareddy V, AvilaOrtiz G. Comparison of two different surgical approaches to increase peri-implant mucosal thickness: a randomized controlled clinical trial. J Periodontol 2018;89:807-814. doi: 10.1002/JPER.17-0597.

2. Linkevicius T, Apse P, Grybauskas S, Puisys A. The influence of soft tissue thickness on crestal bone changes around implants: a 1-year prospective controlled clinical trial. Int J Oral Maxillofac Implants 2009;24:712-719.

3. Mailoa J, Arnett M, Chan HL, George FM, Kaigler D, Wang HL. The association between buccal mucosa thickness and periimplant bone loss and attachment loss: a cross-sectional study. Implant Dent 2018;27:575-581. doi: 10.1097/ ID.0000000000000803.

4. Raes S, Eghbali A, Chappuis V, Raes F, De Bruyn H, Cosyn J.
A long-term prospective cohort study on immediately restored single tooth implants inserted in extraction sockets and healed ridges: CBCT analyses, soft tissue alterations, aesthetic ratings, and patient-reported outcomes. Clin Implant Dent Relat Res 2018;20:522-530. doi: 10.1111/ cid.12613.

5. Sheikh Z, Qureshi J, Alshahrani AM, Nassar H, Ikeda Y, Glogauer M, Ganss B. Collagen based barrier membranes for periodontal guided bone regeneration applications. Odontology 2017;105:1-12. doi: 10.1007/s10266-0160267-0.

6. Thoma DS, Naenni N, Benic GI, Hämmerle CH, Jung RE. Soft tissue volume augmentation at dental implant sites using a volume stable three-dimensional collagen matrixhistological outcomes of a preclinical study. J Clin Periodontol 2017;44:185-194. doi: 10.1111/jcpe.12635.

7. Tonetti MS, Cortellini P, Pellegrini G, Nieri M, Bonaccini D, Allegri M, Bouchard P, Cairo F, Conforti G, Fourmousis I, Graziani F, Guerrero A, Halben J, Malet J, Rasperini G, Topoll H, Wachtel H, Wallkamm B, Zabalegui I, Zuhr O. Xenogenic collagen matrix or autologous connective tissue graft as adjunct to coronally advanced flaps for coverage of multiple adjacent gingival recession: randomized trial assessing non-inferiority in root coverage and superiority in oral health-related quality of life. J Clin Periodontol 2018;45:78-88. doi: 10.1111/jcpe.12834.

8. Froum SJ, Khouly I, Tarnow DP, Froum S, Rosenberg E, Corby P, Kye W, Elian N, Schoor R, Cho SC. The use of a xenogeneic collagen matrix at the time of implant placement to increase the volume of buccal soft tissue. Int J Periodontics Restorative Dent 2015;35:179-189. doi: 10.11607/prd.2226.

9. Lin CY, Chen Z, Pan WL, Wang HL. Impact of timing on soft tissue augmentation during implant treatment: a systematic review and meta-analysis. Clin Oral Implants Res 2018;29:508-521. doi: 10.1111/clr.13148.

10. Huber S, Zeltner M, Hämmerle CHF, Jung RE, Thoma DS. Non-interventional 1-year follow-up study of peri-implant soft tissues following previous soft tissue augmentation and crown insertion in single-tooth gaps. J Clin Periodontol 2018;45:504-512. doi: 10.1111/jcpe.12865.

11. Ghanaati S, Schlee M, Webber MJ, Willershausen I, Barbeck M, Balic E, Görlach C, Stupp SI, Sader RA, Kirkpatrick CJ. Evaluation of the tissue reaction to a new bilayered collagen matrix in vivo and its translation to the clinic. Biomed Mater 2011;6:015010. doi: 10.1088/17486041/6/1/015010.

12. Tal H, Kozlovsky A, Artzi Z, Nemcovsky CE, Moses O. Longterm bio-degradation of cross-linked and non-cross-linked collagen barriers in human guided bone regeneration. Clin Oral Implants Res 2008;19:295-302. doi: 10.1111/j.16000501.2007.01424.x.

13. Brunel G, Piantoni P, Elharar F, Benqué E, Marin P, Zahedi 
S. Regeneration of rat calvarial defects using a bioabsorbable membrane technique: influence of collagen crosslinking. J Periodontol 1996;67:1342-1348. doi: 10.1902/ jop.1996.67.12.1342.

14. Lee JH, Lee JS, Baek WS, Lim HC, Cha JK, Choi SH, Jung UW. Assessment of dehydrothermally cross-linked collagen membrane for guided bone regeneration around periimplant dehiscence defects: a randomized single-blinded clinical trial. J Periodontal Implant Sci 2015;45:229-237. doi: 10.5051/jpis.2015.45.6.229.

15. Chia-Lai PJ, Orlowska A, Al-Maawi S, Dias A, Zhang Y, Wang X, Zender N, Sader R, Kirkpatrick CJ, Ghanaati S. Sugar-based collagen membrane cross-linking increases barrier capacity of membranes. Clin Oral Investig 2018;22:1851-1863. doi: 10.1007/s00784-017-2281-1. 